\title{
Muscle Morphogenesis in Axolotl Limb Regenerates after Removal of Stump Musculature
}

\author{
Bruce M. Carlson \\ Department of Anatomy, University of Michigan, Ann Arbor, Michigan 48104
}

Accepted February 28, 1972

\begin{abstract}
This research was designed to determine whether or not a normal stump musculature is required for normal morphogenesis of muscle within the regenerating amphibian limb. Limbs of adult axolotls were amputated proximal to the elbow, and approximately $99 \%$ of the skeletal muscle was removed from the limb stump. The early stages of regeneration and blastema formation followed a relatively normal morphological and temporal course. In all cases grossly normal limbs regenerated. These regenerated limbs all contained large amounts of muscle, which was usually arranged into anatomically recognizable muscles in both the forearm and hand. It is concluded that muscle morphogenesis in the regenerating amphibian limb is not dependent upon an anatomically normal stump musculature.
\end{abstract}

\section{INTRODUCTION}

Throughout the many decades of research on factors controlling morphogenesis of the regenerating amphibian limb, little attention has been paid to the muscular component of limb regenerates. The cytology of redifferentiating muscle fibers in amphibian limb regenerates has been described by Thornton (1938) and Hay (1962), but descriptive information on the development of entire muscles during limb regeneration is lacking in the literature. Similarly, little experimental effort has been directed toward defining factors that control the morphogenesis of muscles within a regenerating limb. Most of the research which has been done concerns the role of the stump musculature as a determining factor in morphogenesis of the regenerating muscles. Pietsch (1961a) observed that heterotopic stump musculature was associated with muscle abnormalities in larval Ambystoma limbs regenerating after orbital transplantation. In work involving transplantation of regeneration blastemas onto the tail fin, Holtzer et al. (1954) and Pietsch (1961b) reported that in the absence of a disc of stump tissue, muscle does not appear in the regenerate. On the other hand, Stocum
(1968) performed a similar experiment and reported that muscle appeared in $90 \%$ of cone stage transplants and in $100 \%$ of older transplants. A detailed analysis of muscle morphology, however, was not provided.

The present research represents a reexamination of the morphogenetic role of the stump musculature and was designed to answer the following question: Is the presence of morphologically intact stump musculature required for the normal morphogenesis of muscle in the regenerating amphibian limb?

\section{MATERIALS AND METHODS}

The animals used in this experiment were black axolotls (Ambystoma mexicanum) averaging $150 \mathrm{~mm}$ in length. For operations they were anesthetized in 1:1000 solutions of MS-222 (Sandoz) or ethyl $m$-aminobenzoate methanesulfonate (Eastman Chemicals). Postoperatively they were maintained in individual dishes at $20-22^{\circ} \mathrm{C}$ and fed three times a week with beef liver.

Experimental series. Fifty-three forelimbs were amputated just proximal to the elbow, and the skeletal musculature was surgically removed as indicated in Fig. 1. 

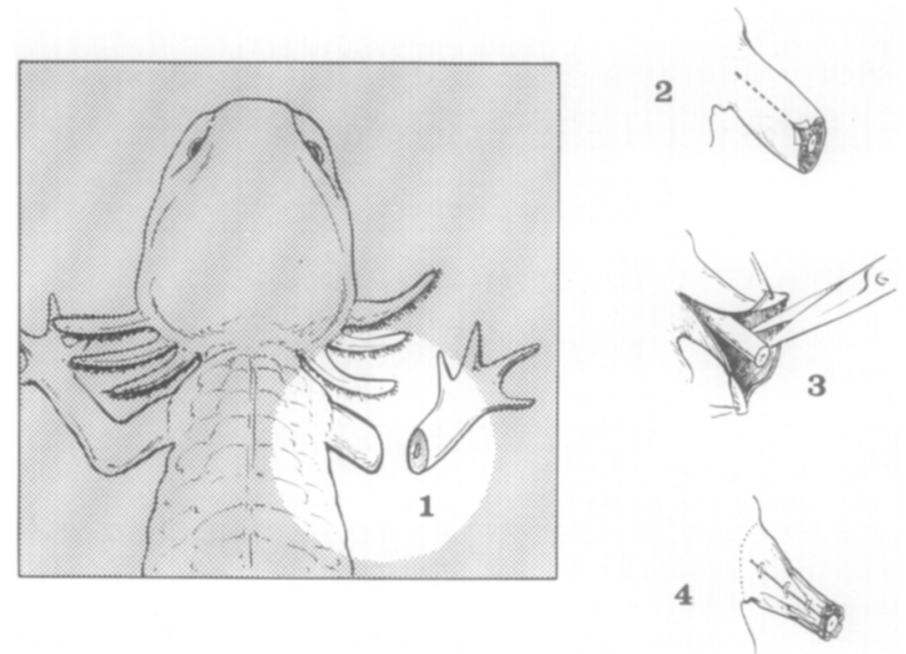

Fig. 1. Plan of the operation. After amputation of the limb just proximal to the elbow (1), a longitudinal incision is made in the dorsal skin (2). The skin is separated from the underlying tissues, and the muscular tissue is removed (3). Major nerve trunks are preserved. Following muscle removal, the dorsal incision is closed with 6-0 surgical silk.

The muscle was removed to the shoulder region (at least $7 \mathrm{~mm}$ proximal to the amputation surface). Operated limb stumps consisted of skin, the humerus, the major nerves and blood vessels and occasional fragments of muscle fibers embedded in loose connective tissue. To prevent the amputation surface from becoming sealed off with full thickness skin (which inhibits limb regeneration) the humerus was allowed to protrude slightly past the amputation level of the skin. Limbs were fixed in Bouin's at intervals from $3 \mathrm{~min}$ to 124 days after the operation. All limbs were serially sectioned transversely or longitudinally at $7 \mu$ and stained with hematoxylin and eosin or Heidenhain's aniline blue.

Normal regeneration controls. In 6 animals one forelimb was amputated and the muscle was removed as described above in the Experimental Series. The contralateral limbs were amputated at the same level but otherwise not touched. These served as controls for normal regeneration. Regenerates of these animals were fixed 88-114 days postoperatively and subjected to serial cross sectional analysis of the muscular pattern.

Normal muscle anatomy. 1. Upper arm. Ten normal upper arms were serially cross-sectioned. These were used to demonstrate the normal muscle morphology in the upper arms and for determinations of number of muscle fibers per cross section.

2. Forearm and hand. All 53 of the originally amputated limbs in the Experimental Series were fixed in Bouin's or formalin solutions. Many of these were dissected grossly or serially cross-sectioned in order to determine the normal pattern of forearm and hand musculature.

Muscle fiber counting. For greater accuracy of reporting, muscle fibers were counted in a number of instances. When large numbers of muscle fibers were involved, cross sections of limbs were projected onto a screen with a Leitz PradoUniversal projector. Although this apparatus produced rapid fading of all stains attempted, counts repeatable within $5 \%$ could be obtained in sections stained with Heidenhain's aniline blue. 
The following cross-sectional muscle fiber counts were made: Upper arm: 7 normal arms and 14 upper arm stumps from the Experimental Series (from $3 \mathrm{~min}$ to 68 days postoperatively). Forearm: the 6 animals comprising the Normal Regeneration Control Series. Muscle fiber counts were made on sections taken at equivalent levels from both the normal regenerates and the regenerates arising from the contralateral demuscled limbs. Accurate muscle fiber counts could not be made on the amputated forearms of these animals because previous trauma (bites by other axolotls) to the hands may have affected the distal forearm musculature. Instead, muscle fibers were counted at the same level in 5 normal forearms from animals about $130 \mathrm{~mm}$ in length. In addition, muscle fibers from two other ran- domly selected forearm regenerates in the Experimental Series were counted.

\section{RESULTS}

\section{Efficacy of Removal of Muscle in Upper Arm}

The validity of this experiment depends completely upon the removal of enough muscle fibers through a sufficient length of the limb stump to preclude the possibility of anything resembling a normal pattern of stump musculature remaining near the amputation surface. In order to provide a baseline value, muscle fibers were counted in 7 normal upper arms at the level indicated in Fig. 2. The average number of muscle fibers in the cross-sectioned limbs at this level is $3404 \pm 129$. Most of the variation in these figures rep-
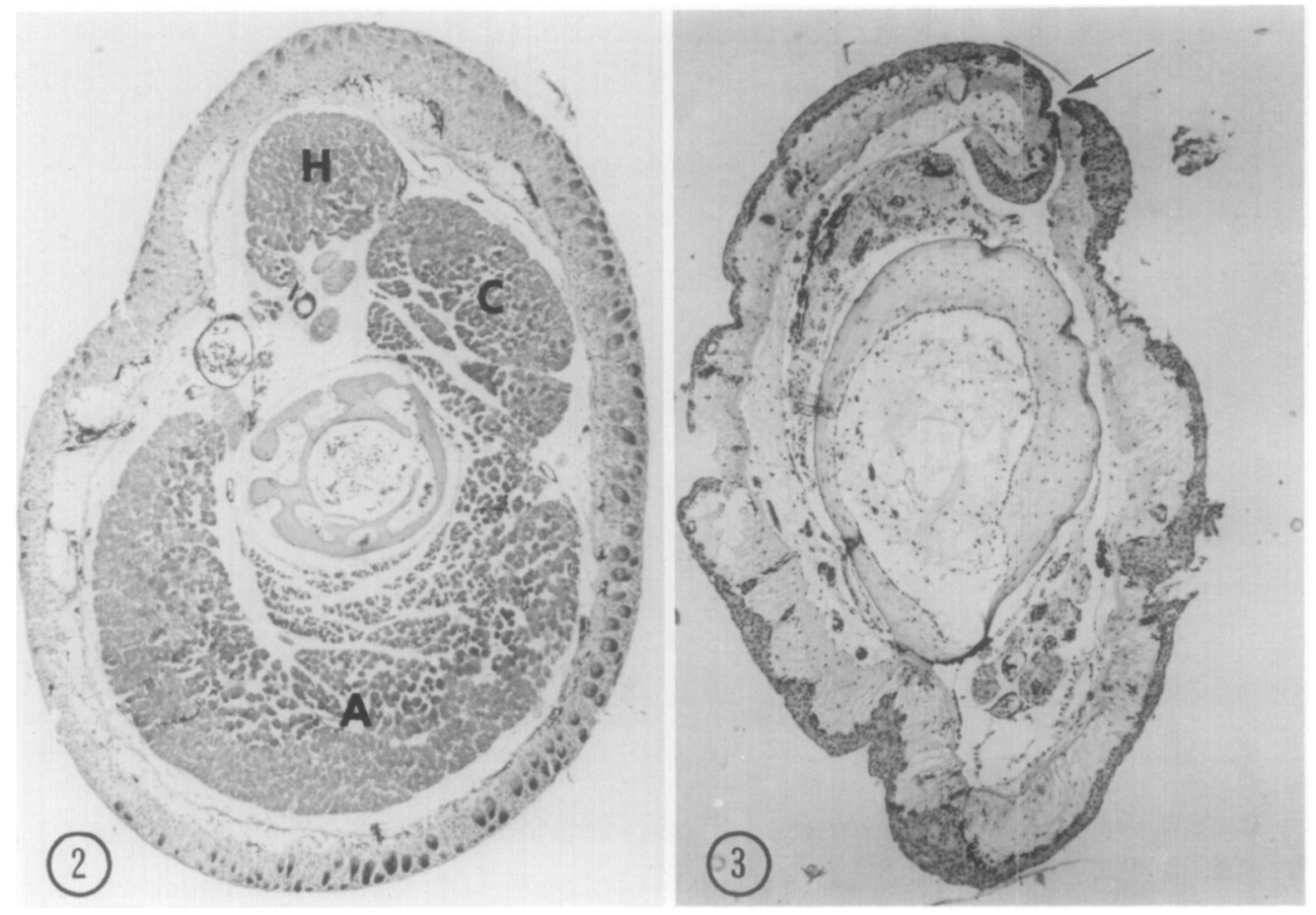

Fig. 2. Cross section through normal upper arm of axolotl. Three muscle masses are present. $A$, anconeus; $H$, humeroantibrachialis; $C$, coracobrachialis longus. Heidenhain's aniline blue. $\times 24$.

Fig. 3. Cross-sectioned limb 3 min after muscle removal. This particular section contains 39 muscle fibers, The major nerve trunks have been preserved. The arrow points to the longitudinal slit made in the skin during the muscle removal operation. Hematoxylin and eosin. $\times 24$. 
resents variation among animals. Muscle fiber counts made on right and left limbs in the same animal agreed within $10 \%$. Among the animals used (total lengths $134-163 \mathrm{~mm}$ ), there was no correlation between total length and number of muscle fibers in the upper arms.

Limb stumps of 12 animals from the Experimental Series were fixed at intervals from $3 \mathrm{~min}$ to 29 days after amputation and muscle removal. Serial histological sections of all limbs were examined to determine the completeness of muscle removal. For each limb, counts of remaining muscle fibers were made at three levels of the stump. In 11 limbs, numbers of remaining muscle fibers per cross section of mid to distal limb stump ranged from 0 to 53 (Fig. 3). A twelfth limb stump contained 114 fibers in a distal cross section. In all sectioned limbs the longitudinal distance between the nonremoved muscle and the amputation surface was at least $5 \mathrm{~mm}$. The discrepancy between this distance and the $7 \mathrm{~mm}$ distance which was stated in the description of the muscle removal operation is due to the retraction of the skin following the operation. In the average limb stump $99 \%$ of the stump musculature was removed for this distance.

\section{Course of Regeneration in Demuscled Limbs}

Except for the virtual absence of the muscular component, the preblastemal phase of regeneration did not seem to differ significantly from that of a normal
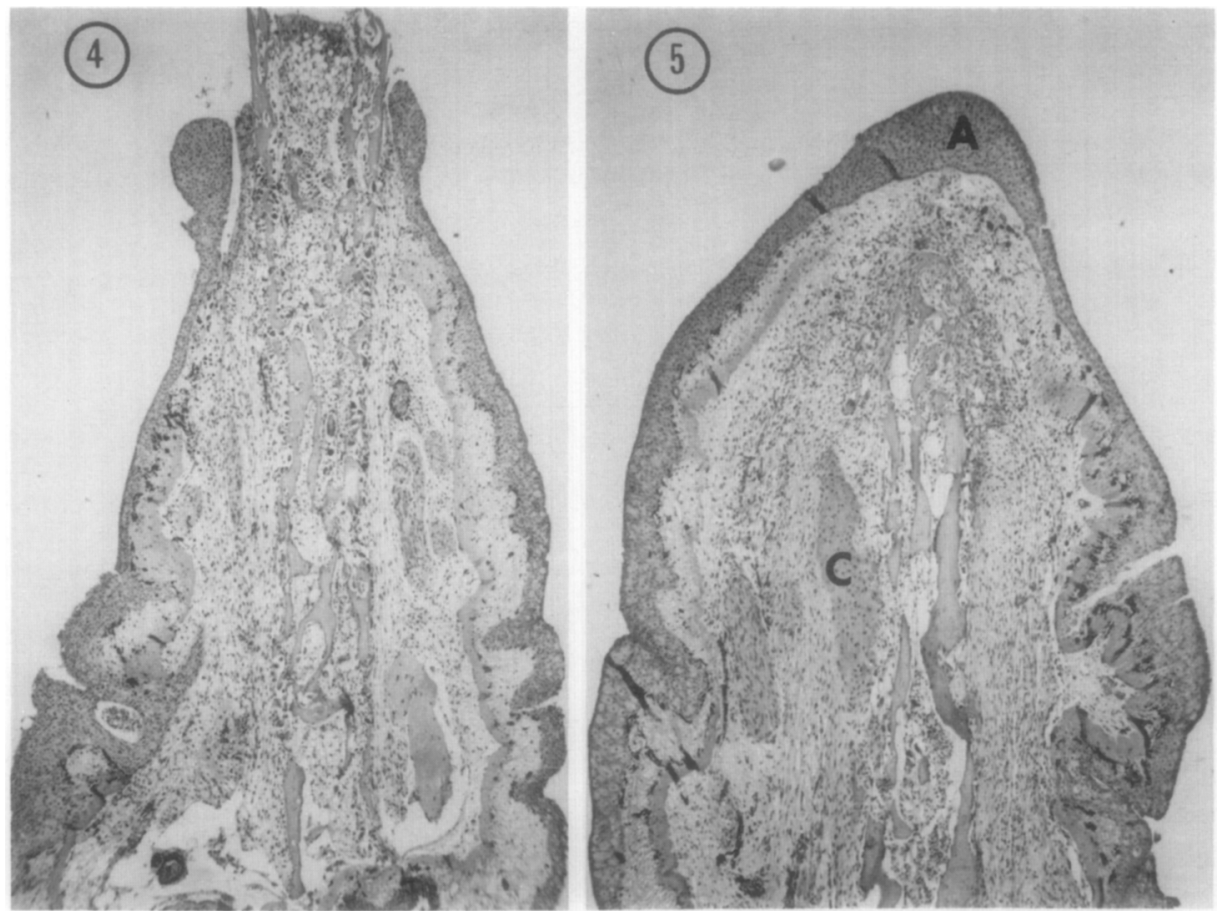

Fig. 4. Longitudinal section through limb stump 10 days after muscle removal. The destructive phase of regeneration is proceeding normally. The protruding segment of bone has prevented complete epithelialization of the wound surface. Osteoclastic activity along the humerus is intense. Almost no muscle fibers are seen in this section. Hematoxylin and eosin. $\times 16$.

Fig. 5. Longitudinal section through limb stump 29 days after muscle removal. This limb possesses a prominent apical epidermal cap $(A)$. Note the differentiation of cartilage $(C)$ along the shaft of the humerus. The dedifferentiative reaction is well underway, and an apical migration of cells to form a blastema has begun. Hematoxylin and cosin. $\times 22.4$. 
limb. Early epithelialization of the amputation surface followed a normal schedule, but because of the segment of humerus which was allowed to protrude past the plane of amputation of the soft tissues, the wound epidermis did not completely cover the amputation surface until early in the third week. The period of destruction and the appearance of osteoclastic erosion of bone followed a normal schedule (Fig. 4). An apical epidermal cap (Fig. 5) was established at about the same time as in control animals, and regeneration proceeded at a normal rate. A blastema developed, and in time a regenerate grossly indistinguishable from normal was formed (Fig. 6).

One difference between demuscled limbs and controls was a greater than usual reaction of the skeletal tissue in experimental limbs to the trauma. The humerus was surrounded by a condensation of cells (Fig. 7), which eventually differentiated into hyaline cartilage (Fig. 5). This cartilage appeared before a blastema had been fully established and is considered to be an example of a direct tissue regenerative process rather than part of the epimorphic regenerative response which involves the passage of cells through a blastema (Carlson, 1970b).

The Morphology of Regenerates Arising from De-muscled Limbs.

Upper arms. In long-term regenerates muscle fibers were found in the upper arms, but in deficient quantities. In the regions proximal to the level of amputation scattered bundles of muscle fibers were present in all regenerates. The number of muscle fibers was considerably less than half of the normal amount, and the anatomical arrangement of the bundles bore no close resemblance to that of

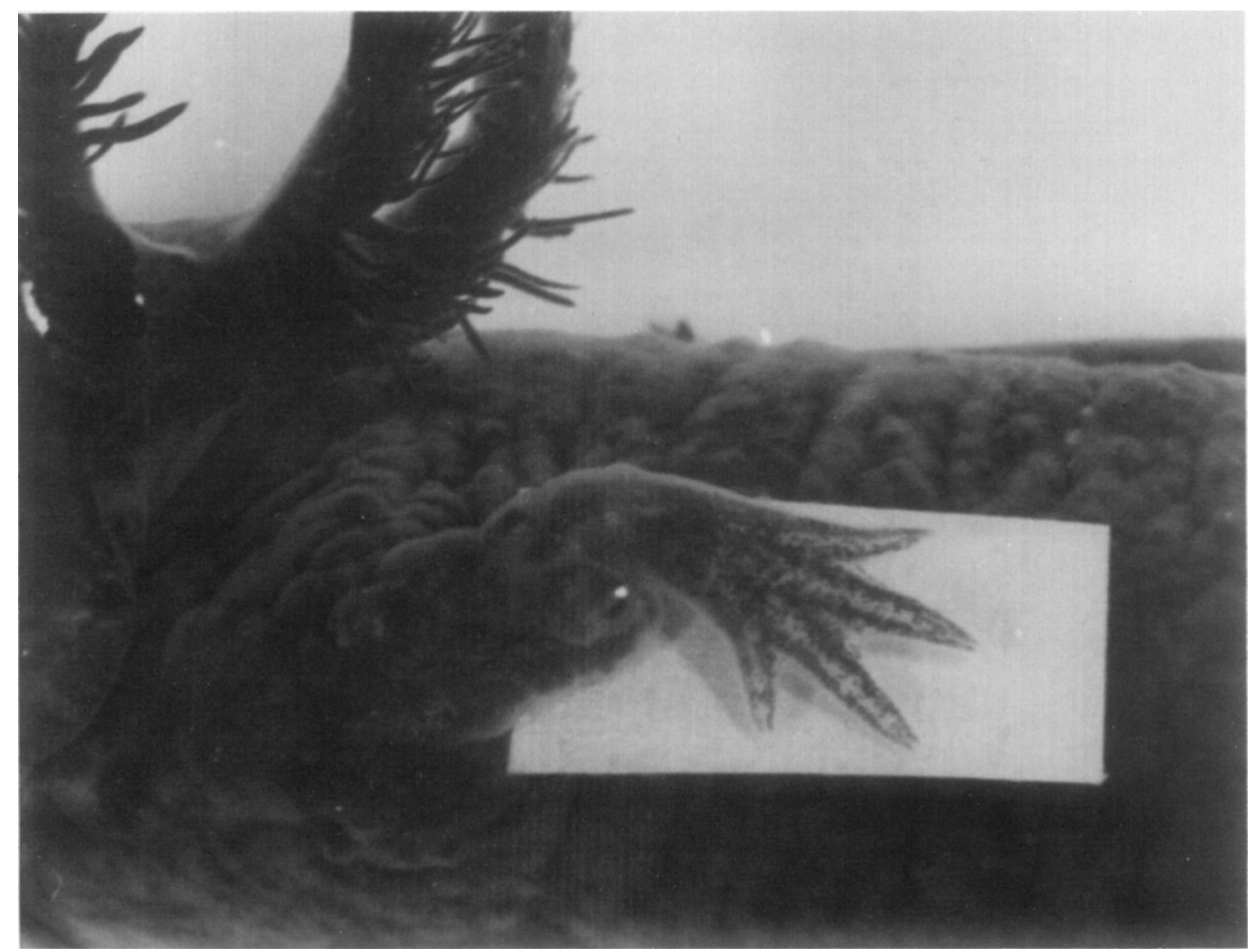

FIG. 6. Grossly normal forearm and hand regenerate 88 days after amputation just proximal to the elbow and removal of musculature of the upper arm. 


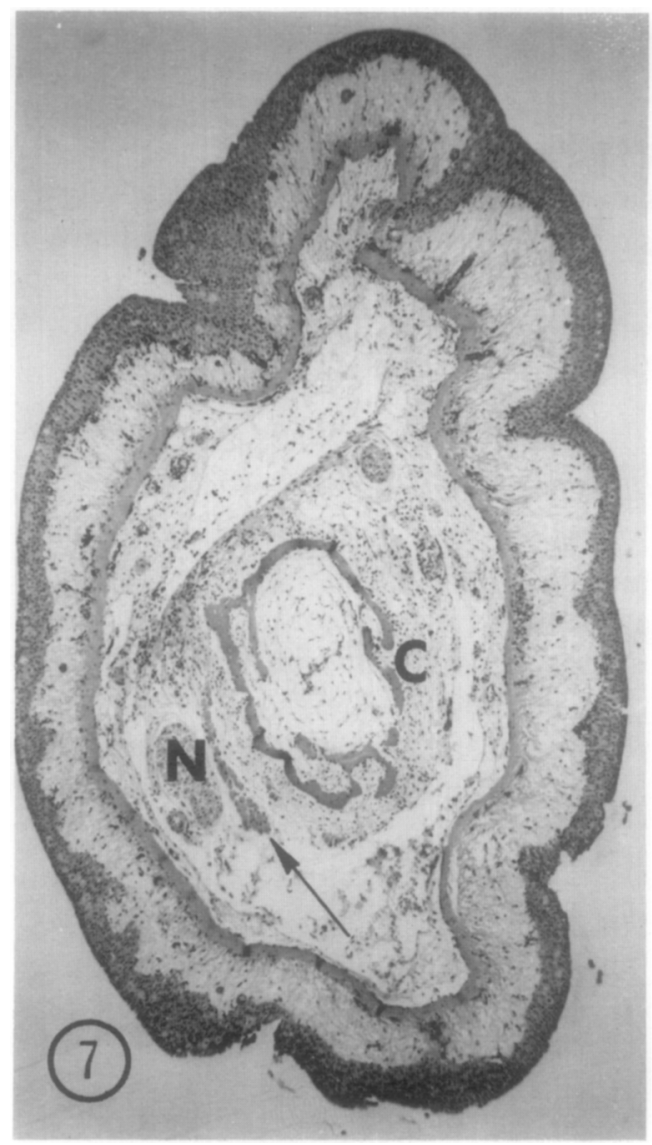

FiG. 7. Cross section through limb stump 12 days after muscle removal. Surrounding the humerus is a cuff of cells $(C)$ which will eventually become cartilage. This limb cross section contains 43 muscle fibers. The arrow points to a clump of remaining muscle fibers. $N$, nerve. Hematoxylin and eosin. $x$ 22.

a normal limb. However, at the most distal levels, near or beyond the level of amputation, muscle patterns resembling the normal configuration appeared in older regenerates (Fig. 8).

Forearms and hands. In all cases regenerated forearms and hands contained numerous muscle fibers. Sixteen crosssectioned mature regenerates from the Experimental Series were compared with both normal forearms and normal forearm regenerates. It was a general rule that most or all of the forearm and hand mus-

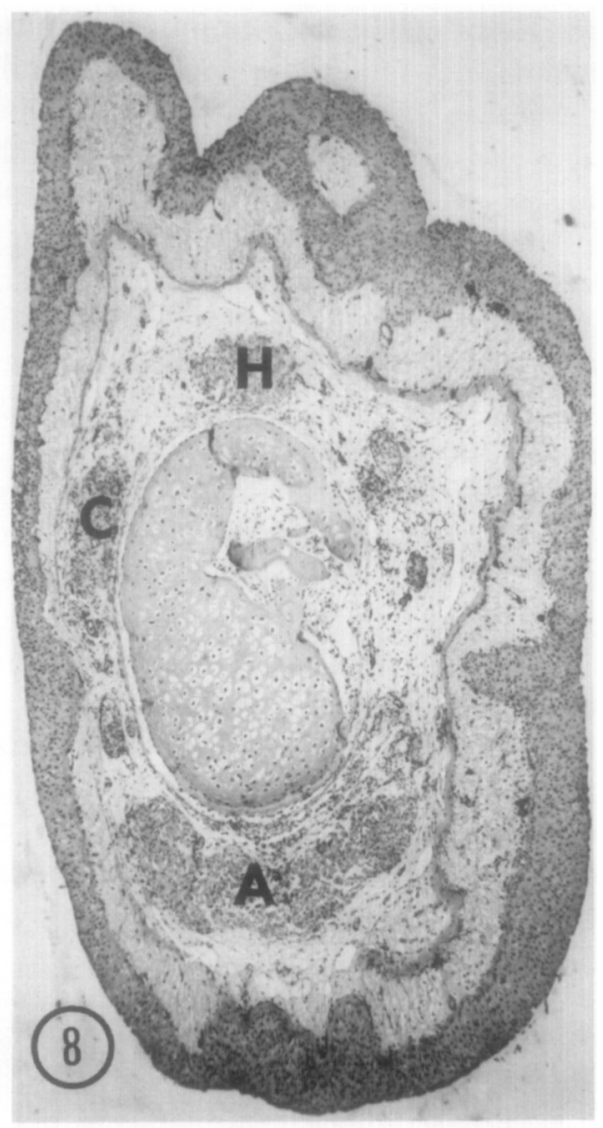

Fig. 8. Cross section through distal upper arm 56 days after amputation and removal of stump musculature. Newly regenerated muscle fibers (identifiable because of their small diameter) have reconstituted muscles closely resembling those of the normal distal upper arm. $A$, anconeus; $H$, humeroantibrachialis; $C$, coracobrachialis longus. Hematoxylin and eosin. $\times 22$.

cles could be identified in the experimental regenerates. Often the muscular pattern in a given cross-sectioned limb was virtually perfect (Figs. 9-11). Occasionally individual muscles, such as the extensor carpi radialis or the extensor carpi ulnaris, were deficient in muscle fibers. In these cases the muscles consisted of relatively dense masses of connective tissue with scattered muscle fibers in them.

As an indication of the degree of resti- 


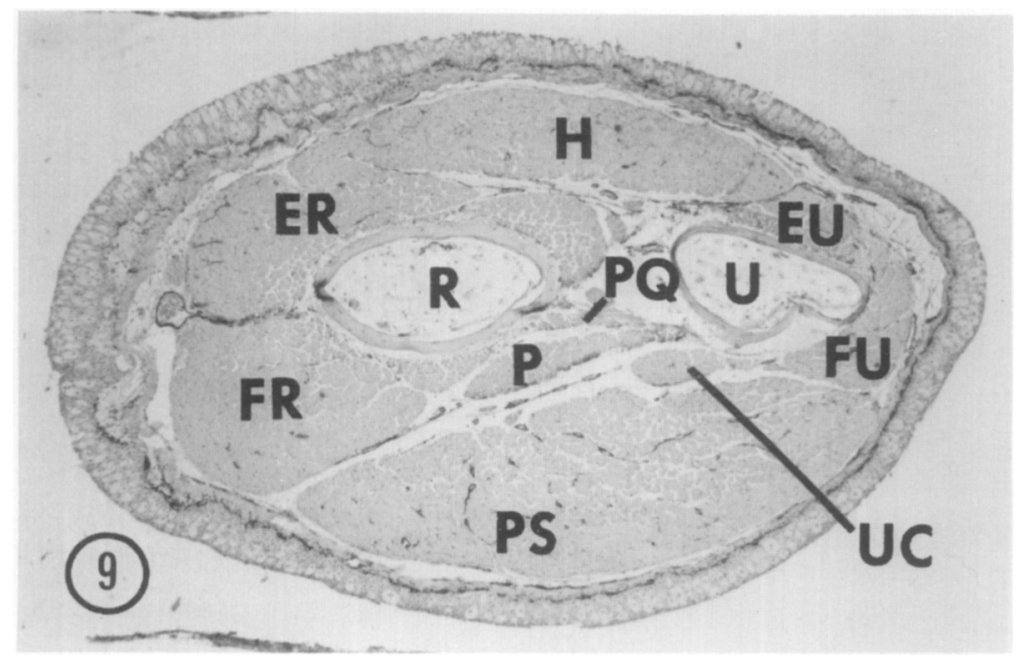

FiG. 9. Cross section through distal segment of normal forearm. The terminology of Blount (1935) has been used for all illustrations of arm musculature. $E R$, extensor carpi radialis; $E U$, extensor carpi ulnaris; $F R$, flexor carpi radiais; $F U$, flexor carpi ulnaris; $H$, humerometacarpalis; $P$, palmaris profundus I; $P Q$, pronator quadratus; $P S$, palmaris superficialis; $R$, radius; $U$, ulna; $U C$, ulnocarpalis. Hematoxylin and eosin. $\times 24$.

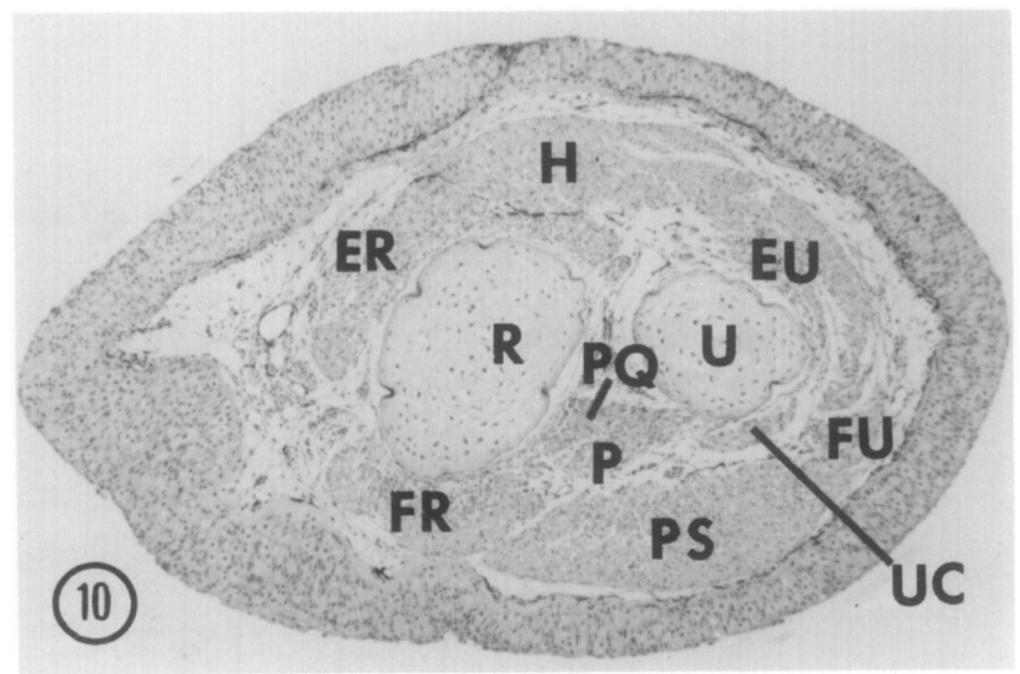

FIG. 10. Cross section through forearm of 88-day regenerate arising from demuscled arm. This section was taken through approximately the same level as the forearm in Fig. 9. The muscle mass in regenerates at this age is considerably less than that of controls because of the small diameter of the muscle fibers. Abbreviations as in Fig. 9. Hematoxylin and eosin. $\times 32$.

tution of the muscle mass, the total number of muscle fibers per cross-sectioned normal and experimental forearm regenerate was counted in the six animals comprising the Normal Regeneration Control Series. In one arm the musculature had been removed from the limb stump whereas the contralateral limb served as a normal regeneration control. All muscle fiber counts were made at the level shown in Figs. 9 and 10. Counts for each animal are shown in Table 1 . A compari- 


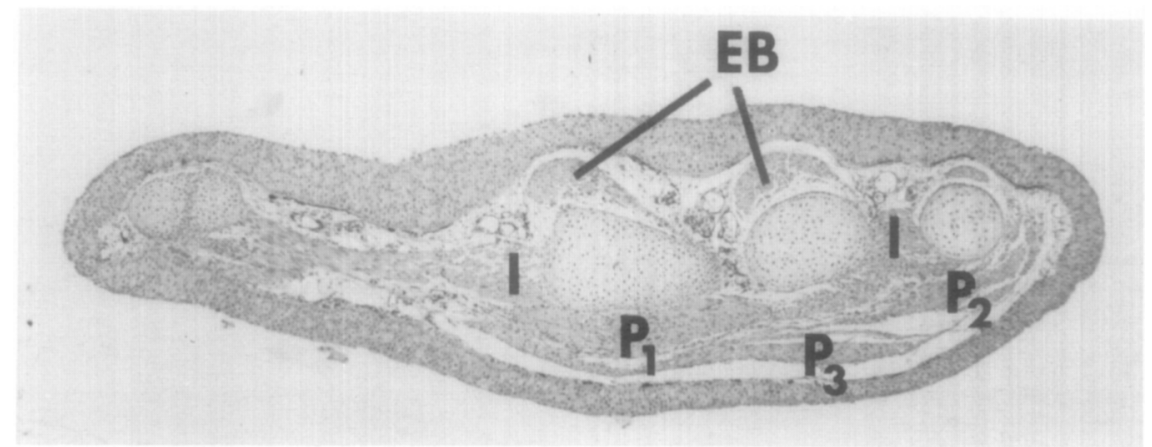

FIG. 11. Cross section through hand of the same regenerate as that shown in Fig. 10. The overall pattern of musculature is essentially normal. $E B$, extensores breves digitorum; I, interossei; P1, palmaris profundus I; P2, palmaris profundus II; P3, palmaris profundus III. Hematoxylin and eosin. $\times 24$.

TABLE 1

Comparison between Number of Muscle Fibers per Forearm Cross Section in Regenerates Arising from Control and Demuscled Limb Stumps

\begin{tabular}{|c|c|c|c|c|c|c|}
\hline Animal No. & 1 & 2 & 3 & 4 & 5 & 6 \\
\hline Total length $(\mathrm{mm})$ & 178 & 158 & 156 & 152 & 150 & 153 \\
\hline Age of regenerate (days) & 96 & 114 & 96 & 88 & 96 & 96 \\
\hline $\begin{array}{l}\text { Muscle fibers/cross section, } \\
\text { control limb }\end{array}$ & 6458 & 5596 & 6690 & 4573 & 4200 & 4814 \\
\hline $\begin{array}{l}\text { Muscle fibers/cross section, } \\
\text { demuscled limb }\end{array}$ & 6874 & 3370 & 5410 & 4765 & 3794 & 3110 \\
\hline
\end{tabular}

son of the muscle fiber counts of experimental limbs does not reveal a consistent pattern relative to that of the controls, but it leaves little doubt that ample numbers of muscle fibers appear in limb regenerates even after removal of most of the stump musculature. Muscle fiber counts at the same level of the forearm in two additional regenerates (78 and 118 days) from the Experimental Series revealed 6280 and 4442 muscle fibers, respectively. Among the 5 normal forearms in which muscle fiber counts were made, the mean number of fibers was 5335 .

\section{DISCUSSION}

The results of this experiment leave little doubt that an intact stump musculature is not required for the normal morphogenesis of muscles within a regenerating limb. Even though occasional defects of individual muscles were noted, the overall muscular patterm of these regenerates was consistently close to normal. As a rule the musculature of the hand and distal forearm was normal, but deviation from the normal pattern could sometimes be seen in the proximal forearm. In the only other comparable work, Holtzer (1970) mentioned some unpublished experiments in which radical extirpation of muscle proximal to the plane of amputation resulted in regenerates containing either no or very little muscle. Since neither the species nor the age of the experimental animals was mentioned, it is difficult to compare this observation with the present experiment. A number of years ago, Polezhaev (1937) removed the mesodermal tissues from limb stumps of axolotls, minced them, and then replaced the minced tissue into a cuff made by the skin of the limb stump. After a healing period, the "sausage" was reamputated and normal regeneration ensued. Although detailed anatomical evidence was not presented, the author stated that a normal 
skeleton and musculature were present in the regenerates. Thus in Polezhaev's experiments, also, anatomical perfection of the stump musculature was not a requirement for the normal morphogenesis of regenerating limb muscles.

Using a different approach, Pietsch (1961a, 1962) concluded that the musculature of limb regenerates is causally related to preexisting muscle. He transplanted larval Ambystoma limbs into the orbit and allowed the extraocular muscles to grow into the limb musculature. When these limbs with mixed musculature were amputated, regenerates containing a normal skeleton, but abnormal muscle appeared. Pietsch suggested that whatever mediates myogenesis operates at both the histogenic and morphogenic level and that it is a concomitant of muscle already present in the limb stump. This interpretation would not be incompatible with the results of the present experiment although it by no means represents the sole alternative. A necessary assumption would be that the muscle of the regenerate arises from preexisting muscle cells. This has not been ascertained. If the morphology of muscles in a regenerate is a manifestation of an overall organization directed by "morphogenetic field" influences inherent in the entire limb stump, then only a source of myogenic cells, susceptible to field control, would be required. In contrast, if total control of myogenesis resided in the precursor cells of muscle alone, then the character of the stump musculature would be all important. As will be discussed below, cytodifferentiation in regenerating mammalian muscle can occur without the expression of intrinsic morphogenetic controls (Carlson, in press $a, b$ ). It would be of considerable interest to determine whether in the nonepimorphic or tissue mode of regeneration of muscle in the amphibian limb (Carlson, 1970a) cytodifferentiation is similarly dissociated from overall morphogenetic control.
There is a striking parallel between limb muscle and skeleton with respect to the ability of the outgrowing regenerate to cope with deletions or additions in the limb stump. It has been known for years that following limb amputation and removal of the skeleton of the stump in amphibians, a new limb possessing an anatomically normal skeleton regenerates despite the absence of differentiated skeletal elements in the stump (Fritsch, 1911; Weiss, 1925). Goss (1956) has also demonstrated that the morphogenetic controls of the regenerating limb are unable to cope with the addition of an extra skeletal element to the stump, and in that case supernumerary skeletal elements appear in the proximal portions of the regenerates. There were no abnormal skeletal elements, however, in the distal parts of the regenerates in Goss' experiments. In the case of muscle, as well as skeletal tissues, the regenerating limb seems fully capable of ordering a normal set of morphogenetic events despite a deficiency of either tissue in the limb stump, but it has difficulty in erasing additional or foreign sources of morphogenetic information. This latter circumstance results in anatomical abnormalities of the homologous tissue within the regenerate.

One of the most puzzling aspects of this investigation has been the source of the cells which turn into muscle fibers within the regenerates. In contrast to studies involving removal of the skeleton from the limb stump it can not, of course, be said here that a potential source of precursor cells has been entirely removed. Both the remaining muscle fibers in the limb stump and the damaged muscle fibers at the base of the limb could, in theory, serve as the sole source of myogenic cells for the regenerate. Neither pinched off myonuclei nor satellite cells can be mathematically ruled out as percursor cells of the new muscle. Because of the tremendous mass of muscle removed from the limb stump, there would have to be a major burst of 
proliferative activity to compensate for the removed material if muscle were the sole source of myoblasts. In view of the low percentage of satellite cells in axolotl muscle ( 2 of 50 nuclei, or $4 \%$, Flood, $1971 ; 9$ of 330 nuclei, or about $3 \%$, Carlson and Rogers, unpublished data), proliferation would have to be particularly intense if satellite cells alone were to participate in myogenesis. A possible conversion of connective tissue cells to myoblasts must also be kept in mind. By means of double labeling experiments, Steen $(1968,1970 a, b)$ has demonstrated considerable instability of phenotypic expression in some cells of the regenerating limb and considerable stability of other types. Substantial numbers of chondrocytes arose from grafts of labeled fin connective tissue or muscle (containing both muscle and connective tissue cells), but grafts of labeled chondrocytes were quite stable. Few labeled muscle nuclei were found in regenerates after implantation of labeled fin connective tissue into the limb. The possibility remains, however, that the absence or scarcity of a normal precursor cell may push other types of cells in the regenerating limb to differentiate along pathways different from normal in order to compensate for the deficit.

Experiments by others have indicated that under certain experimental circumstances a deficiency of stump musculature results in regenerates with a corresponding reduction in muscle mass. Holtzer et al. (1954) and Pietsch (1961b) reported that following deplantation of early limb blastemas (6-10 days) into the tail fin of Ambystoma larvae, regenerates possessing little or no muscle appeared. Transplantation of older blastemas (1115 days) resulted in the frequent appearance of muscle in the regenerates (Pietsch, 1961b). If a blastema with a disc of stump tissue was deplanted, the subsequent regenerates possessed a normal complement of muscles (Pietsch, 1961b). Un- fortunately, transplantation of a blastema with a disc of stump tissues not containing muscle was not performed. Also working on Ambystoma larvae, Stocum (1968) observed normally arranged striated muscle in $90 \%$ of regenerates following transplantation of cone-stage blastemas without accompanying stump tissue. $\mathrm{He}$ indicated that the amount of muscle formed in blastemal transplants was "slightly less" than in whole blastemas transplanted with stump. The difference between the amounts of muscle seen in the experiments of Pietsch and Stocum suggests that variations in experimental conditions may have been in part, responsible for the discrepancies. S. Holtzer (1956) surgically removed masses of muscle from one side of tail stumps in $A m b y$ stoma larvae. The regenerates possessed muscular deficiencies which corresponded to the location and extent of the deficiency in the stump. These results are contrary to those observed in the present experiment and may be a reflection of a fundamental difference between the regenerating limb and the regenerating tail.

Despite the demonstration that a limb regenerate can develop a normal muscular component in the absence of an anatomically intact stump musculature, we still know very little about the manner in which actual muscle morphogenesis is accomplished. Studies on the regeneration of minced mammalian muscles have shown that although the myoblastic cells are fully capable of complete cytodifferentiation, they are apparently unable to express any information which would bring about their alignment into parallel bundles or their aggregation into entire muscles (Carlson, in press $a, b$ ). These phases of morphogenesis in a tissue regenerative system can be accounted for entirely upon the basis of pressure, tension, and functional relationships with surrounding tissues. The regenerating limb, however, appears to represent a considerably different and more complex 
morphogenetic system. From studies on Ambystoma larvae continuously anesthetized in MS-222 during the progressive phase of limb regeneration, it can be said that function of the limb is not required for normal morphogenesis of muscle in an epimorphic regenerative process (Carlson, in press a). There are indications that the myogenic cells themselves possess or receive usable morphogenetic information which can be expressed during an epimorphic regenerative process and that association with the regeneration blastema is required for the expression of that information. Nevertheless, definitive statements must be based upon the results of more critical experimental evidence than is presently available.

\section{REFERENCES}

Blount, I. W. H. (1935). The anatomy of normal and reduplicated limbs in amphibia, with special reference to musculature and vascularization. J. Exp. Zool. 69, 407-457.

Carlson, B. M. (1970a). The regeneration of a limb muscle in the axolotl from minced fragments. Anat. Rec. 166, 423-436.

Carlson, B. M. (1970b). Relationship between the tissue and epimorphic regeneration of muscles. Amer. Zool. 10, 175-186.

Carlson, B. M. (In Press a). Organizational aspcets of muscle regeneration. In "Research in Muscle Development and the Muscle Spindle" (R. J. Przybylski and B. G. Banker, eds.). Excerpta Medica, Amsterdam.

Carlson, B. M. (In Press b). "The Regeneration of Minced Muscles." Karger, Basel.

Flood, P. F. (1971). The three-dimensional structure and frequency of myo-satellite cells in trunk muscle of the axolotl (Siredon mexicanus). J. Ultrastruct. Res. 36, 523-524.

Fritsch, C. (1911). Experimentelle Studien über Regenerationsvorgänge des Gliedmassenskelets der Amphibien. Zool. Jahrb. 30, 377-472.

Goss, R. J. (1956). The relation of bone to the histugenesis of cartilage in regenerating forelimbs and tails of adult Triturus viridescens. J. Morphol. 98, 89-123.

Hay, E. D. (1962). Cytological studies of dedifferentiation and differentiation in regenerating amphibian limbs. In "Regeneration" (D. Rudnick, ed.), pp. 177-210. Ronald, New York.

Holtzer, H. (1970). In discussion of Steen (1970b), pp. 85-87.

Holtzer, H., Avery, G., and Holtzer, S. (1954). Some properties of the regenerating limb blastema cells of salamanders. Biol. Bull. 107, 313 (Abstract).

Holtzer, S. W. (1956). The inductive activity of the spinal cord in urodele tail regeneration. $J$. Morphol. 99, 1-39.

Pietsch, P. (1961a). The effects of heterotopic musculature on myogenesis during limb regeneration in Amblystoma larvae. Anat. Rec. 141, 295-303.

Pietsch, P. (1961b). Differentiation in regeneration. I. The development of muscle and cartilage following deplantation of regenerating limb blastemata of Amblystoma larvae. Develop. Biol. 3, 255-264.

Pietsch, P. (1962). Independence of chondrogenesis from myogenesis during limb regeneration in $\mathrm{Am}$ blystoma larvae. J. Exp. Zool. 150, 119-127.

Porfzhafv, L. V. (1937). Concerning the determination of regenerates (Russian). In "To Academician N. V. Nassonov (Russian)," pp. 151-247. Izdatel. Akad. Nauk SSSR, Moscow

STEEN, T. P. (1968). Stability of chondrocyte differentiation and contribution of muscle to cartilage during limb regeneration in the axolotl (Siredon mexicanum). J. Exp. Zool. 167, 49-78.

Steen, T. P. (1970a). Origin and differentiative capacities of cells in the blastema of the regenerating salamander limb. Am. Zool. 10, 119-132.

SteEN, T. P. (1970b). Cell differentiation during salamander limb regeneration. In "Regeneration of Striated Muscle, and Myogenesis"' (A. Mauro, S. A. Shafiq, and A. T. Milhorat, eds.), pp. 7390. Excerpta Medica, Amsterdam.

Stocum, D. L. (1968). The urodele limb regeneration blastema: a self-organizing system. II. Morphogenesis and differentiation of autografted whole and fractional blastemas. Develop. Biol. 18, 457480.

Thonnton, C. S. (1938). The histogenesis of muscle in the regenerating fore limb of larval Amblystoma punctatum. J. Morphol. 62, 17-47.

WEISs, P. (1925). Unabhăngigkeit der Extremitätenregeneration vom Skelett (bei Triton cristatus). Arch. Entwicklungsmech. Organismen 104, 359 394. 